\title{
MODALITIES OF VALORISATION AND PROMOTION OF CULTURAL HERITAGE THROUGH ICT: ADDING NEW MILESTONES TO THE “STANDARD” PRACTICE
}

\author{
C. Tommasi ${ }^{1}$
}

1Dept. of Architecture, Building environment, and Construction engineering (ABC), Politecnico di Milano, Milano, Italy - cinzia.tommasi@polimi.it

KEY WORDS: Cultural Heritage, Digital Humanities, Communication, Valorisation, Best Practice, People engagement

\begin{abstract}
:
Nowadays, in the academic field, it is growing the demand for digital competencies bounded to advanced communication strategies. More and more national and international project required to the scientific community to be increasingly open to new targets of public, even not expert one. The focus point is that the research must be accessed not only by professionals, but it has to engage a broader public, starting from local communities to the public of the web. This statement is testified by the European funds calls that ask for communication activities and strategies, along with dissemination and exploitation. Why these three activities are so important? Because they are strictly related to the impact that a project can have, not only for the academic world, but also for the outside. This trend is growing fast in each scientific field: also in Cultural Heritage conservation, where it is more and more common the uses of 3D digital models not only for maintenance purposes, but also as a bridge between the heritage and non-expert publics. The question is how advanced digital techniques can help the process of valorisation of Cultural Heritage at different stages?

The article wants to look for a standard practice to promote and enhance Cultural Heritage using digital technologies. Through the analysis of a series of case studies, it wants to show how to build a valorisation strategy, considering all the components of $\mathrm{CH}$, and how it can be implemented adding new disciplines and skills (communication and promotion), enhancing users' access and interaction.
\end{abstract}

\section{INTRODUCTION}

\subsection{What is digital in Cultural Heritage field?}

The word "digital" is associated with Cultural Heritage definition, given during the European Year of Cultural Heritage 2018. According to this statement, Cultural Heritage has a universal value for communities and societies, and it is important to pass it on future generations. The components of $\mathrm{CH}$ are tangible, intangible, natural, and digital.

Tangible is everything with a physical dimension (monuments, buildings, artefacts, and other); intangible is the oral traditions, craftsmanship, legends, knowledge, skills, and others; natural is landscape, flora, fauna; and finally digital is the resource created in digital format (e.g., "digital twins") or the ones digitalised for guaranteeing the conservation (text, images, videos, registrations, and more).

What emerges from this definition is how much it is crucial for Cultural Heritage projects to be shared, participated, and communicated to different kind of targets, but also how much digital became part of the standard practices for the conservation of $\mathrm{CH}$, becoming an opportunity for pursuing the objective of pass it on the future generation, and to ease the access to the monuments and site, even if they are inaccessible or destroyed.

The topic is emerging and has a key role at international level, as testified by the six programmes of Societal Challenges under Horizon 2020 that supported it (EU, 2021):

- curation of digital assests and advanced digitisation (2018)

- European cultural heritage, access and analysis for a richer interpretation of the past (2017)

- cost-effective technologies for advanced 3D modelling to enhance the understanding of cultural heritage and Innovation Ecosystems of Digital Cultural Assets, Virtual Museums (2014-2016)
In this framework, it is clear the vital role of the communication and promotion in this field, which can help the digital heritage becoming a bond between the scientific research and society.

\subsection{The topic of communication in the European framework}

Communication, dissemination and exploitation are activities that bring the research to the attention of as many relevant people as possible, which is one of the main requests from the national and international funding programs.

The European Commission explains the differences between these three terms, which regard the objective, the targets, the channels, and the impact of the activity (Table 1).

As emerged from Table 1, the communication is an important action aimed to inform, promote, and engage different targets of public, not belonging to the scientific community. What it is important thought, is to remember that the actions aimed to these objectives are not an end in themselves and the communication activity needs to be strategically planned and exposed through a Communication Plan and an editorial calendar (Interreg V-A, 2014). The Communication Plan (CP) is a shared document at disposal of each project's partner that contains the objectives of the communication and how the project wants to achieve them. Usually it identifies the specific activities, the time-schedule, the targets, the governance, the channels of communication.

This strategy can help publicise the project in such a way that the partners will profit. Suitably framed messages can help to:

- Increase the success rate of the proposal (through the CP)

- Draw the attention of national governments, regional authorities and other public and private funding sources to the need for and ultimate benefits of the research

- Attract the interest of potential partners 
- Encourage talented students and scientists to join the partner institutes and enterprises

- Enhance the visibility at local, national and international level

- Help the search for financial backers, licensees or industrial implementers to exploit the results

- Generate market demand for the products or services developed

\begin{tabular}{|c|c|c|c|}
\hline & Communication & Dissemination & Exploitation \\
\hline Purpose & $\begin{array}{l}\text { Promoting } \\
\text { actions and } \\
\text { results }\end{array}$ & $\begin{array}{l}\text { Making the } \\
\text { results public: } \\
\text { open science }\end{array}$ & $\begin{array}{l}\text { Making } \\
\text { concrete use } \\
\text { of results }\end{array}$ \\
\hline Target & $\begin{array}{l}\text { Citizens, } \\
\text { communities, } \\
\text { media, } \\
\text { stakeholders }\end{array}$ & $\begin{array}{l}\text { Scientists, } \\
\text { authorities, } \\
\text { industry, } \\
\text { policymakers, } \\
\text { sectors of } \\
\text { interest }\end{array}$ & $\begin{array}{l}\text { Those that } \\
\text { can make } \\
\text { good use of } \\
\text { them: } \\
\text { authorities, } \\
\text { industrial } \\
\text { authorities, } \\
\text { policymakers, } \\
\text { sectors of } \\
\text { interest, civil } \\
\text { society }\end{array}$ \\
\hline Modality & $\begin{array}{l}\text { Having a well- } \\
\text { designed } \\
\text { strategy } \\
\text { Conveying } \\
\text { clear messages } \\
\text { Using the right } \\
\text { media, web, } \\
\text { social channels }\end{array}$ & $\begin{array}{l}\text { Publishing } \\
\text { your results } \\
\text { on, scientific } \\
\text { magazines, } \\
\text { scientific } \\
\text { and/or } \\
\text { targeted } \\
\text { conferences, } \\
\text { databases } \\
\end{array}$ & $\begin{array}{l}\text { Creating } \\
\text { roadmaps, } \\
\text { prototypes, } \\
\text { softwares } \\
\text { Sharing } \\
\text { knowledge, } \\
\text { skills, data }\end{array}$ \\
\hline Timing & $\begin{array}{l}\text { From the start } \\
\text { of the project } \\
\text { until the end }\end{array}$ & $\begin{array}{l}\text { At any time, } \\
\text { and as soon as } \\
\text { the project } \\
\text { has results }\end{array}$ & $\begin{array}{l}\text { Towards the } \\
\text { end and } \\
\text { beyond, as } \\
\text { soon as the } \\
\text { action has } \\
\text { exploitable } \\
\text { results }\end{array}$ \\
\hline Impact & $\begin{array}{l}\text { - Engage with } \\
\text { stakeholders } \\
\text { - Attract the } \\
\text { best experts to } \\
\text { your team } \\
\text { - Generate } \\
\text { market demand } \\
\text { - Raise } \\
\text { awareness of } \\
\text { how public } \\
\text { money is spent } \\
\text { - Show the } \\
\text { success of } \\
\text { European } \\
\text { collaboration } \\
\text { - Legal } \\
\text { obligation: } \\
\text { Article } 38.1 \text { of } \\
\text { the Grant } \\
\text { Agreement }\end{array}$ & $\begin{array}{l}\text { - Maximise } \\
\text { results' } \\
\text { impact } \\
\text { - Allow other } \\
\text { researchers to } \\
\text { go a step } \\
\text { forward } \\
\text { - Contribute } \\
\text { to the } \\
\text { advancement } \\
\text { of the state of } \\
\text { the art } \\
\text { - Make } \\
\text { scientific } \\
\text { results a } \\
\text { common good } \\
\text { - Legal } \\
\text { obligation: } \\
\text { Article } 29 \text { of } \\
\text { the Grant } \\
\text { Agreement }\end{array}$ & $\begin{array}{l}\text { Lead to new } \\
\text { legislation } \\
\text { - For the } \\
\text { benefit of } \\
\text { innovation, } \\
\text { the economy } \\
\text { and the } \\
\text { society } \\
\text { - Help to } \\
\text { tackle } \\
\text { a problem } \\
\text { and respond } \\
\text { to an existing } \\
\text { demand } \\
\text { - Legal } \\
\text { obligation: } \\
\text { Article } 28 \text { of } \\
\text { the Grant } \\
\text { Agreement }\end{array}$ \\
\hline
\end{tabular}

Table 1. The differences between the communication, dissemination, and exploitation activities of a research project, according to European Union Grant Agreement (EU, 2019).
Considering the presented framework, communication can play an essential role in Cultural Heritage conservation projects, being an active part of the valorisation process, the part that uses strategies and actions to engage and approach communities to the project's process, results and usage.

\subsection{Valorisation in $\mathrm{CH}$ field}

The article 6 of the Italian Cultural Heritage Code defines $\mathrm{CH}$ valorisation as a relational dimension of the safeguarding and conservation (Petraroia, 2014). The objective of this "inclusive" and communicative approach of the valorisation is the integration between enjoyment and co-responsibility, between public actions and citizens and society initiatives. In this vision, the valorisation of $\mathrm{CH}$ includes each intervention that improves the conservation condition of a building, requiring an aware behaviour to access the heritage, also considering the restitution of a utility value contemporary to the society and territory where the building belongs. The main four pillars of the valorisation are:

- Centrality of the heritage in relationship with the local society: opportunities for the reference society and its territory, respecting the historical, urban, structural, and typological conditions

- Sustainability: cultural sustainability as warranty of $\mathrm{CH}$ centrality in long-term period for the local community; social sustainability as the maintenance of an identity social function; economic sustainability as direct or indirect support to the local development

- Ability to generate effective and positive impacts on the $\mathrm{CH}$, local community, and territory

- Ability to generate and consolidate new relationships networks in the local environment and towards outside, as unprecedented cooperation and care forms, growth of the community experiences, opportunities of attraction and production of positive cultural, social, and economic phenomena

Summarising, as the valorisation of $\mathrm{CH}$ is a relational dimension of conservation, it is necessary to promote joint initiatives for supporting the knowledge and awareness of the $\mathrm{CH}$ related to the territorial environment, to stimulate in the population the perception of the culture investment as an essential assumption of the capital development of the territory, rather than a "losing" cost.

In this complex framework, Cultural Heritage definition assumes a holistic view, and the challenges for ensuring its valorisation, management, preservation, and promotion address to these lines: the communication between different actors and disciplines, the technology that can be the mean to deal with the large amount of data and can connect people, widening the public through participatory processes, and the quest for a "standard" (Dávila-Lorenzo and Saladrigas-Medina, 2020) practice that can be shared at national and international levels. For this reason, the methodology of the $\mathrm{CH}$ conservation projects should include the technical aspects bonded to the conservation and safeguarding of $\mathrm{CH}$, and on the other hand, the social science context: to rise the cultural perception and awareness it is necessary to use participatory processes and to study the communication and the channels to employ according to the target.

The "fil rouge" that puts together the technical and social aspects of the valorisation definition could be the digital technology, as part of the $\mathrm{CH}$ definition by European Year of Culture 2018, and as a consistent part of the world of today. 


\section{DIGITAL USAGE AND FRUITION IN CH FIELD}

In a structure of Cultural Heritage impact for valorisation and fruition, where is "digital" located? The language used for valorisation projects belongs to the new technologies (virtual, digital, multi-media) and their products are emotional experiences, created to surprise the public in a vision of "edutainment" - education and entertainment. "Digital experiences are transforming how audiences engage with culture and are driving new forms of cultural participation and practice. As technology advances, so do the behaviours of audiences, especially younger audiences. We are no longer passive receivers of culture; increasingly we expect instant access to all forms of digital content, to interact and give rapid feedback (UK Department for Digital, Culture, Media \& Sport, 2018)".

The Digital Innovation Observatories published a report 2018 analysing the level of digitalisation of the Italian cultural institutions: only $22 \%$ of institutions own an officialised digital innovation plan and a strategic plan. The most technological activities are communication and fruition "in loco"; in fact, the transmission and customer care are also the fields where the institutions choose to invest. Instead, the services on the museum sites are growing. The statistics presented also speak about the main activities of digital innovation plans: after communication and customer care, the second and third place of the list is "cataloguing and digitalisation of the collection" and "planned conservation/real-time monitoring of the heritage". These two activities testify the great interest for the cultural institutions that have started to invest in projects of valorisation that involve the digitalisation of the monuments and sites, and the people engagement.

Moreover, the Covid-19 pandemic situation became an opportunity in 2020 for the cultural institutions to change their business models and improve the digital actions. In 2020, the Digital Innovation Observatories report that the $80 \%$ of the Italian museums offer at least one digital content, where the $69 \%$ published its digital collection. The $45 \%$ of the institutions propose on-line laboratories and learning activities, as virtual tours and online visits (45\%).

The digital channels are not anymore only tools for promotion, services, and information, but in this framework become tools for sharing the knowledge and cultural awareness. The digital is an opportunity to re-think the user experience, in the time and space, as not bonded to a specific space and the time of the inloco experience, but potentially a continuous and accessible experience in every space and every moment.

Considering this background, the main areas where digital is employed in $\mathrm{CH}$ field are services (on-line ticketing, management); communication (websites, social networks, apps, and more); monitoring (individual experience, personalised contents, feedback); 3D models (conservation, communication, experiences, gamification, prototyping, and more).

At this point, focusing on 3D models, it is interesting to see how they are accessed in $\mathrm{CH}$ and what are the uses and targets to contribute to the valorisation and communication.

\subsection{Fruition typologies}

What are the uses of the collected data in a $\mathrm{CH}$ project? In the previous section was underlined that $3 \mathrm{D}$ models are one of the most requested digital products from the cultural institution, as it can have multiple uses, not only targeted to professional, but also to wider public. The 3D models can be employed for conservation, dissemination, live experiences, gamification, and prototyping purposes (Figure 1).

From these categories of usage, it is possible to study three main typologies of fruition/access and users:

- Fruition aimed to the maintenance and restoration activities (expert users)

- Fruition intended to the public, especially regarding the valorisation of the object from real to virtual, e.g. virtual museums, ad hoc platforms, and more (nonexpert users)

- Fruition targeted to a marketing strategy, taking advantage of the local heritage to create new products (cultural and creative industries users)

\subsection{Fruition aimed to the maintenance and restoration}

The first example regards the fruition aimed to restoration activities and management, implemented in sharing platforms to connect different expertise or expert users with non-expert users. The keywords in these cases are web-sharing, restoration, multi-data platforms. In the last years, the researchers used 3D models as an "ordinary" element useful for restorers' analyses, because of the better understanding of the structural and morphological features of the heritage. However, the data of Cultural Heritage are often sectorial, and they are generated from heterogeneous applications, which are maybe not compatible between each other's, and stored by different bodies. The 3D modelling is still a time-consuming phase for the conservation of $\mathrm{CH}$, and often it does not give the possibility to insert and consult the different kind of data in an easy and practical way.

An example that fits in the description above, of platforms the maintenance activities of $\mathrm{CH}$ is the online system BIM3DSG (Tommasi, et al. 2019; 2020; Achille et al., 2019; Fassi et al.

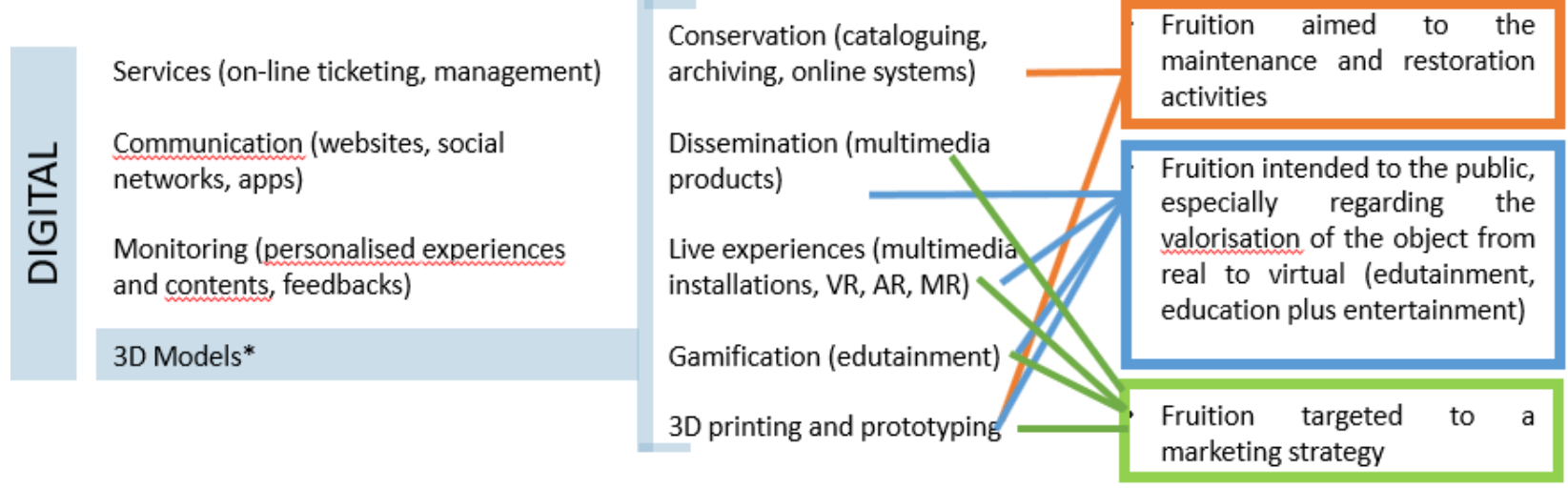

Figure 1. The usage of 3 models in CH Field, and how these products can be accessed by different users, according to the purpose of the research. 
2012; Mandelli et al., 2017).

This platform is developed by 3DSurvey Group at Politecnico di Milano. It is an adhoc system created time by time on the specific needs of the case study. It was born in 2008 (called WEBBIM3D) to meet the need of managing the huge 3D model of the main spire of Milan Cathedral. During the years, it evolved into a flexible system called BIM3DSG (Figure 18) capable to handle:

- Development using co-design strategies and bottomup approach (users involved from the early stages of design)

- 3D models coming almost from any software

- Point clouds

- Structured information - possibility to customise the database

- Images

- Hi-resolution orthophotos

- Repository and download of the data of dwg, pdf, word, xls, and more

- Hotspots for assigning punctual data

- Monitoring the life-cycle of the building through the creation of restoration interventions

- Possibility to insert glossaries and shared vocabularies

- Multiple queries

The benefits derived by these features are:

- $\quad$ Safeguarding the Cultural Heritage

- Easing the access to Cultural Heritage from multiple users

- Georeferencing the 3D models

- Building Cultural services on demand for the citizens

- Smart management of the Cultural Heritage and its information system

- Sharing the contents (information, knowledge, itineraries, and more)

- Cultural awareness raising

- Possibility to use the information database for crowdfunding purposes.

Today, there are lots of different case studies managed by this web-interface, including buildings, statues and artworks, archaeological sites, and cities. Each database has several fixed attributes common to all the others plus some specific features that change according to the needs of the single case study. For this reason, potentially, the target of this platform can be both the fruition aimed at maintenance and conservation activities, both the fruition intended more to the public, thanks also to the visualisation of the objects from real to virtual (edutainment, education plus entertainment). In this way, the platform becomes a tool for the action of "participatory design", pointing to social enterprise and generating an eco-system of services, actors and stakeholders. They can produce new value sequences in the fields of production and collaborative fruition of cultural services (Figure 2).

\subsection{Fruition aimed to edutainment: non-expert public}

On the other hand, the 3D models can also be the base to create multi-media products for engaging people through an emotional experiences and edutainment.

Giving users the possibility to interact with data, as well as create their own content and upload it into libraries' collections may increase public ownership and responsibility of the individual towards the cultural assets, while building virtual communities and user groups. At the same time, digital social engagement may help libraries achieving those goals they would never have the time, financial or staff resource to achieve on their own (Holley, 2010).

The contribute to the cultural institution by the online community requires different types of interaction including correction and transcription tasks, contextualization, complementing collection, classification, co-curation, and crowdfunding (Oomen et al., 2011), depending on whether it is intended to pursue the quantity or quality of the contributions.

This kind of approach employs digital storytelling, not simply showing the models, but creating a story around it. In this case, the keywords of these case studies are storytelling, cross-media approach, emotional installations, gamification, experience, and edutainment. In fact, in the contemporary "cross-media age" characterized by the spread of user-created contents enabled by the proliferation of free platforms for sharing - the traditional portrait of a passive and predictable audience is now anachronistic and inapplicable to the case of the contemporaneous prosumers or "Consum-Authors". In the marketing domain, while the term 'consumption' implies degradation, the term 'use' implies repeatability in relation to commercial goods; in the cultural domain, in which words such 'use', 'fruition', or 'experience' - which imply a relationship between cultural assets and users - already have replaced the term 'consumption' because of the renewable intrinsic value of heritage. In fact, the notion of 'relational good' rather than 'durable good' better describes the nature of cultural assets characterized by proprieties of relational identity, reciprocity,

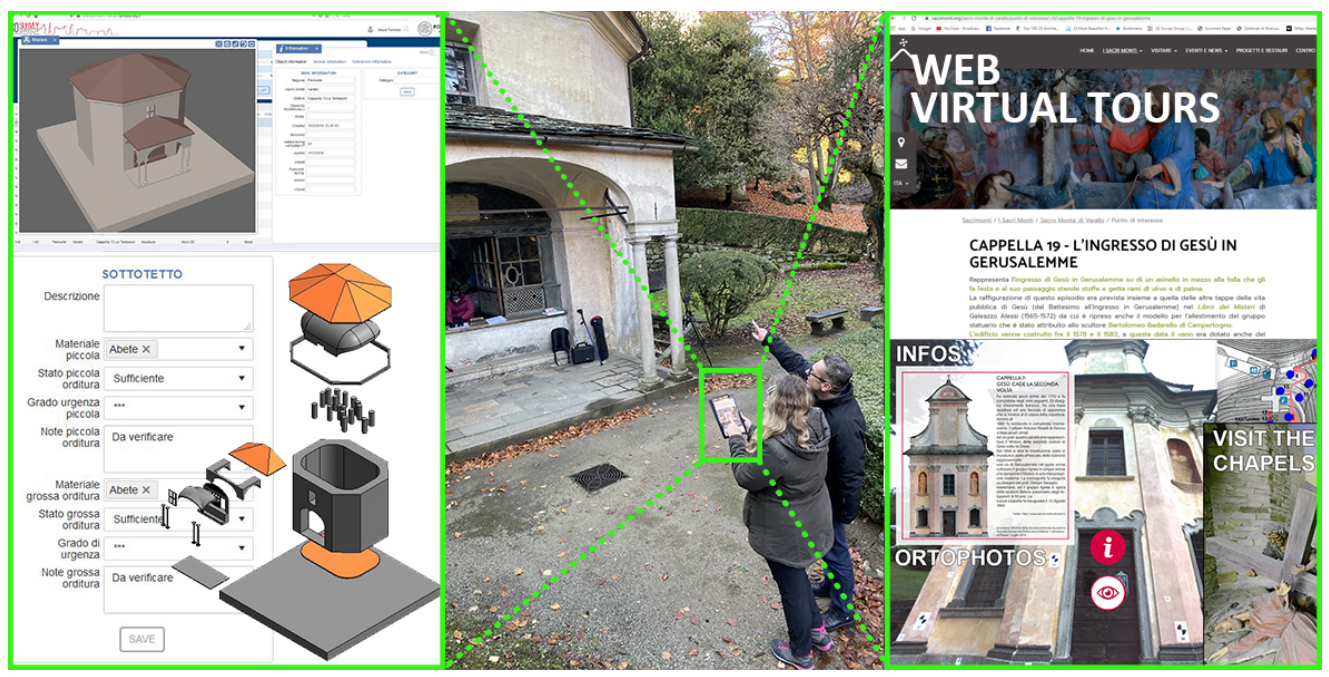

Figure 2. BIM3DSG can be an useful tool for accessing the heritage including but not limited to conservation purposes. 
simultaneity, and openness.

Sometimes, it is possible that these products are part of a bigger strategy of territorial marketing or of communication in big events. This is the case of 3D model of Madonnina Statue (Figure 3), made for conservation purposes and employed for other two different uses both targeted to non-expert users.

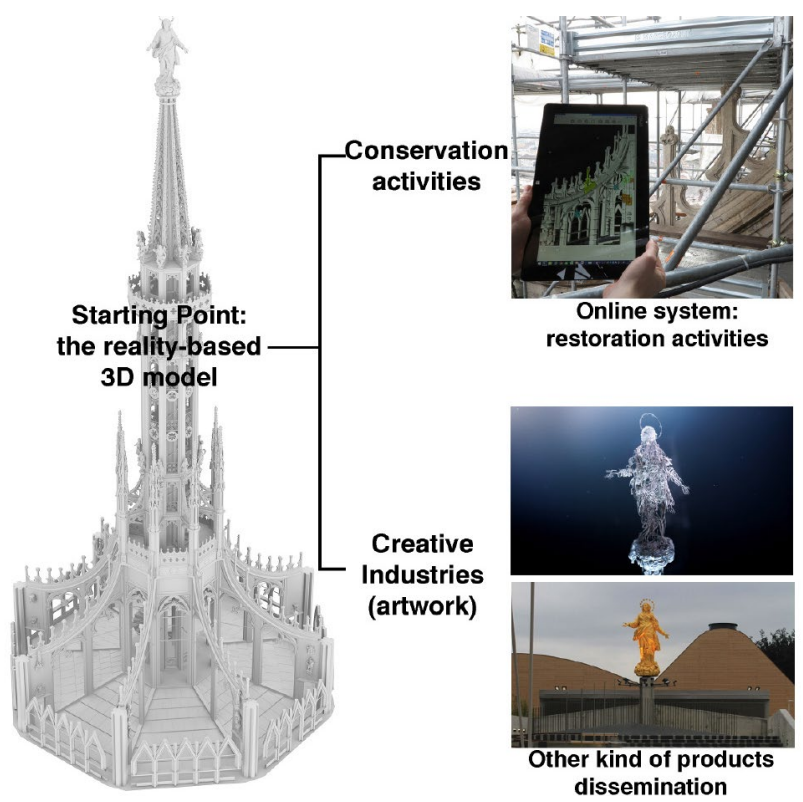

Figure 3. From the model made for conservation purposes, it is possible to extract other kind of products, useful for the dissemination and fruition to non-expert public.

First, the artist Tobias Wüstefeld used the reality-based model made by Politecnico di Milano (Fassi and Achille., 2015) to make an artistic video for the Digital Design Days event that took place in Milan in April 2018. In this case the output is a video trailer where the artist shows different parts of Milano almost "wireframe", all connected in a net. The sound and the lights inside the video help the emotional path and seems like the different monuments has a beating heart inside them.

The second example starting from the same 3D model is the $1: 1$ printed replica of the Madonnina, the statue on the top of Duomo di Milano. In fact, in 2015, the 1:1 copy of the statue was printed for the event EXPO 2015, and then moved to the apse of the Church, where it is still located now. In this way, it is easier for the public to access to this very important symbol of the city, which otherwise is at $108 \mathrm{~m}$ from the ground, and it is possible to admire it only from distance. Another use of the replicas is bonded to Milan's tradition: since last century, the city did not permit to the buildings to be higher of Duomo di Milano and Madonnina (which is on the top) because the statue had to see and protect the entire city. Nowadays this law decayed, and Milan now is full of new skyscraper higher than the Cathedral. The replicas' job is to continue to maintain the tradition, because every time a new tall building is built, the copy is placed on the top of the building.

On the other hand, cross-media approach and digital storytelling can also help the territorial marketing: Experience Etruria is a nice example. This project aims to communicate the culture and the traditions of a territory through $3 \mathrm{D}$ models, videos, and a CGI24 character. The result is a web platform, where it is possible to explore the territory through a map and several itineraries proposed (water, wine and salt, oil and wheat, woods, exhibitions), using multi-media videos to educate and entertain people on the specific topics.

The storytelling and the cross-media approach are also highlighted in the project "Isabella d'Este Virtual Studiolo" by VisitLab CINECA. The result is an emotional video trailer realised mixing sounds, effects, 3D models, and images, looking for funding agencies to restore Isabella d'Este's study room, in Ducal Palace in Mantua.

Another emotional product that merges a 3D model with holographic techniques and 3D architectural mapping (Catanese, 2013) is the exhibition "The Etruscans and the Afterlife" developed by VisitLab Cineca for the Museum of the History of Bologna. The object is the Sarcophagus of the Spouses of National Etruscan Museum of Villa Giulia, in Rome. The main objectives of the project were:

- To produce a full-scale 3D visualisation

- To minimise technological barriers between the exhibit and visitors

- To involve the entire exhibition space of the museum in the storytelling context

- To make the installation transportable, reproducible, and adaptable to other exhibition spaces

The result is an installation of a 1:1 3D model inside a custommade three-sided holographic pyramid (4 $\mathrm{m}$ wide, $3 \mathrm{~m}$ high) and a 3D architectural mapping on a surface of $360 \mathrm{~m} 2$, creating an immersive audio-visual environment.

The last-mentioned experiences use storytelling and crossmedia approach (Figure 4) to create emotional paths for different aims as promoting a monument to collect funding or turning into virtual an object and make it accessible in another city or museum. Another use of 3D models can also involve the gamification and edutainment tasks. For example, MUVI Virtual Museum of Daily life - 1930s, is a virtual environment located in a fascist village near Bologna, Italy, designed by a rationalist architect Francesco Santini and inaugurated in 1926. It composed by three areas: an external village, the interiors with daylight and nightlight. The interiors contain furniture and objects that reconstruct the design of that period, also telling the political life. The aim is to explore the objects of the everyday life and discover more about that historical period.

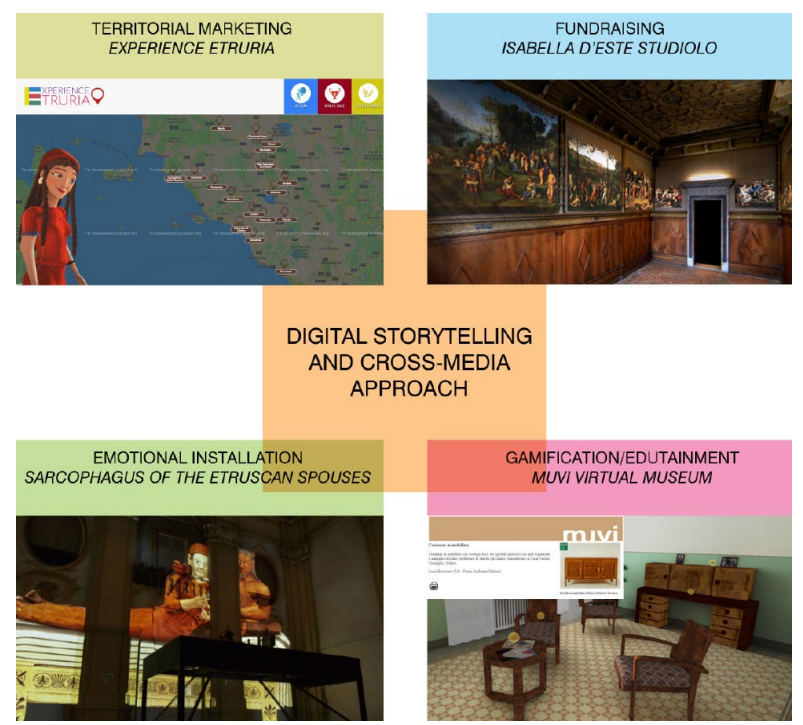

Figure 4. Starting from digital storytelling and cross-media approach it is possible to apply the 3D models in several ways and for multiple scopes: territorial marketing, fundraising, emotional installations, and gamification. 


\subsection{Fruition targeted to a marketing strategy - industry supply chains}

The cross-sectorial operations have significant potential in creating an active scientific and political marketplace that understands and combines various traditions, methods and languages. The reference and replicable model that represents the integrated approach is the structure of the CCPS (Cultural and Creative Productive System), a set of productive activities and enterprises that aim to produce new values and occupation.

The Cultural Core of this system contains four sectors (Unioncamere, 2018):

- Activities of conservation and valorisation of Cultural and Artistic Heritage

- Non-replicable operations of cultural services, represented by live shows, concerts, and more, called Performing Arts

- Replicable activities, represented by cinema, radio, gaming, publishing, and more, called cultural industries

- Creative industries, represented by communication, design, architecture

The core (Figure 5) aims to produce value to strengthen the Cultural Heritage and stimulate the community processes, following the strategic lines of culture, identity, training, and innovation (Della Torre, 2015). Culture because it is the wire that bonds together all the activities of the system; identity because giving access to culture means to produce citizenship, engagement, and sense of responsibility; training because people become the players for the next actions; innovation because economy, social, culture, and environment are integrated together producing territorial capital. Moreover, it is interesting to see how 3D models and digital can be included in the four categories of CCPS, testifying that they correctly participate in the innovative vision of Cultural Heritage impact.

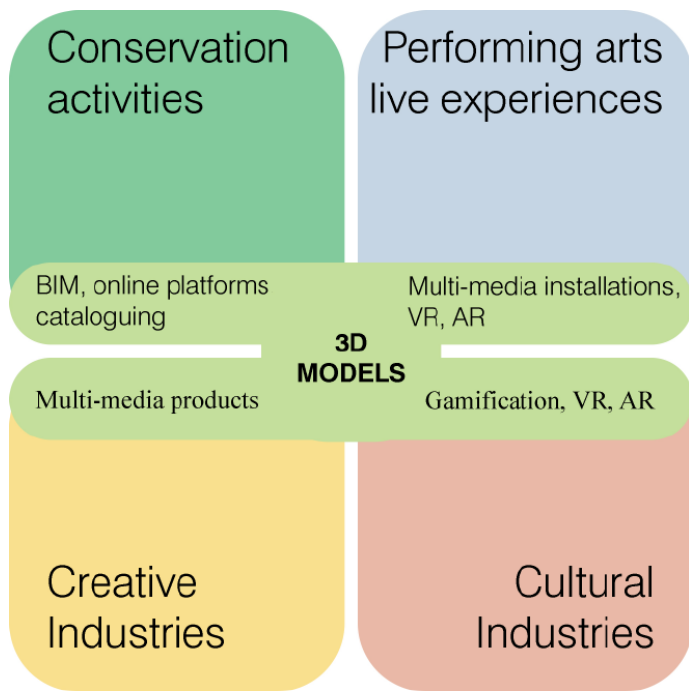

Figure 5. The core of the CCPS, combined with the most common uses of $3 \mathrm{D}$ models.

The resources for culture come from sectors that stimulate social cohesion, labour market, regional development, creative industries, and more. In this case, the perspective of Cultural Heritage impact is "upstream" (Figure 6), meaning that the starting point of the process of valorisation is the mix of sectors that contaminate each other in a trans-sectorial collaboration and multi-layered framework.
The result is a unique flow that goes towards the territorial reactivation.

The conservation activities, performing arts, creative and cultural products, and social engagement, are not the consequences of the process but they are the assumptions.

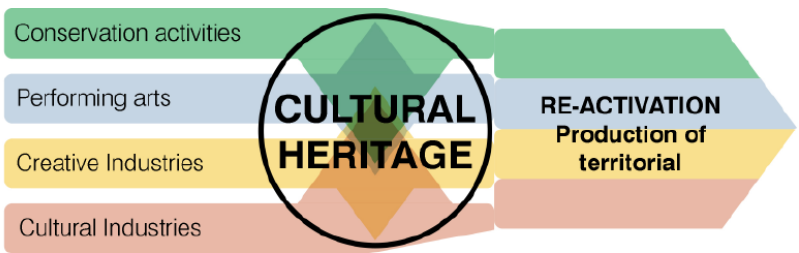

Figure 6. The upstream perspective on $\mathrm{CH}$ impact. Source: Cultural Heritage Counts for Europe - CHCFE, 2015.

An example that fully uses the upstream framework is "Distretti Culturali" - Cultural District (Tartaglia and Fanzini, 2017). This project included a wide Italian area and started from 2009 cofinanced by Cariplo Foundation, an Italian matching grant program. The aim is to produce a new attitude toward culture as a factor of local development and a cross-disciplinary cutting role. Culture, research, education, social, and economy are the strategic lines. It is possible to say that in this project, according to the needs of each of the six areas involved, all the four parameters of the four-leaf clover scheme where touched. In this case, the use of digital was limited and not fully developed. The future direction could be to strengthen the co-design process, including digital tools that can improve the social relationships and people engagement, building a bridge between the expert users and non-expert users from the early stages of the project.

Valorisation of $\mathrm{CH}$ means to act towards the diffusion of the knowledge and the recognition of the values of the heritage itself, as mentioned above. For this reason, the communication is essential. The case studies showed has in common that all are pursuing the goal of access and promotion of the heritage through 3D models and digital, even if the target of the users can be different (expert, non-experts, both). In fact, the 2.1 section shows how web-based platforms can help the restoration activities and connect different professionals and information in a unique interface. Models richer of information are also of great interest for the communities that can discover the conservation activities in progress in a heritage, or visualise it preparing the visit. Section 2.2 investigates different uses of digital and 3D model, which are more focused on storytelling, cross-media approach, emotional involvement, and gamification. The vision is that $\mathrm{CH}$ and digital can produce values and relationships if the products are shared and disseminated among an investigating community.

\section{CONCLUSION}

The collection of examples inside the article is not exhaustive, but it is significant to represent what is happening and the evolution of these products, which confirms the necessity of finding efficient methods for sharing different kind of information with diverse user's targets. The techniques discussed in the previous sections aim to introduce the theme of an effective and strategic communication for the access and promotion of $\mathrm{CH}$. The examples described highlights some modalities to access the heritage, operated by a series of solutions that let to explore and learn about the site from remote. Digital becomes tool of site managing oriented for an expert public, an improvement of the visit experience, accessing original contents and building itineraries before the visit, can overcome the disabilities, being a tool for social inclusion when 
the public is not physically able to go on site (e.g. for physical disabilities or economical reason), and can also represent the "digital twin" of a certain heritage, when it is destroyed by natural or human actions (e.g. cataclysms or terrorist attacks). From the analysis of the case studies, it is possible to extrapolate some valorisation criteria for Cultural Heritage: conservation, education, community engagement, cultural access and participation, and sustainability (Figure 7).

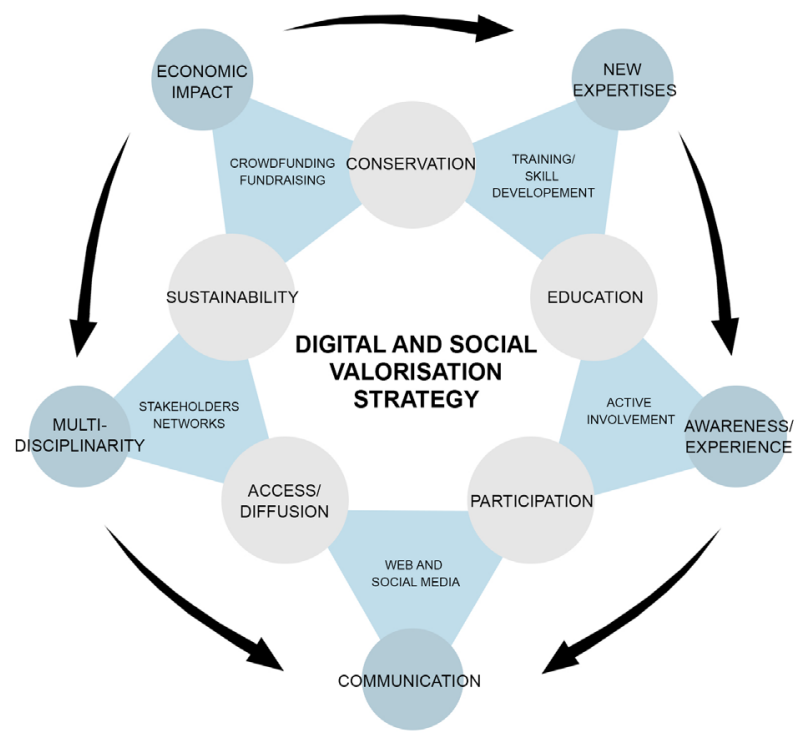

Figure 7. the criteria founded in Chapter 2.4 highlight their interactions and the areas of convergence.

The conclusion is that the article wants to look for a standard practice to promote and enhance Cultural Heritage using digital technologies. Through the analysis of a series of case studies, it wants to show what is the main common workflow of conservation and valorisation of $\mathrm{CH}$, and how it can be implemented (Figure 8), adding new disciplines and skills (communication and promotion). The richness of the 3D models is not in the details of the shapes that it represents, it is instead in the interpretation process behind them, and how it is built to support the information. The kind of content required to engage a non-expert public needs tools that should use digital storytelling, having in mind the relationship between material and virtual: the latter should not deny the first, but integrate it, adding contents and information.

Participatory conservation includes a series of activities such as informing, listening, understanding, consulting, involving, collaborating, and empowering, which help to: facilitate dialogue between all actors; mobilise and validate popular knowledge and skills; apply and adapt the science; and support communities and their institutions to manage and contrail resource use. As well as this it seeks to achieve sustainability, economies, equity, social typology, justice and the preservation of cultural integrity. In this context the new participatory conservation approaches act at three levels:

- Documentation and prevention through communication and information sessions, for example: interactive seminars and workshops, interviews, pho ne-ins, email networks and voluntary agreements

- Investigation and research through inclusion of community members in interdisciplinary scientific research teams and through innovative, integrative and participatory methods for cultural and environmental education, analysis and sharing like: Participatory Learning and Action, Living Labs, and IT platforms, e-learning technologies and online apps (survey, analysis and monitoring)

- $\quad$ Storage and display: exhibitions using traditional and modern infographics, digital methods, augmented reality, project mapping, etc (Spiridon et al., 2015)

From this framework, it is possible to say that for supporting the valorisation process, the methodology should comprehend at least three main phases: a knowledge phase, where it is possible to collect and acquire all kind of data, tangible and intangible; modelling phase, where a $3 \mathrm{D}$ model is build as most flexible tool for support information and sharing contents among different categories of public, and a sharing phase, where it is important to communicate and promote $\mathrm{CH}$, using the appropriate channels.

In the end, a reflection on the new competencies to acquire to manage the whole conservation and valorisation process is mandatory, considering not only the education and training of expert users, but also the developing of people awareness and engagement. Nowadays, it is emerging an intermediary role between the field of digital technologies and the socio-cultural aspect bonded to the intangible elements of the heritage: a digital humanities expert in $\mathrm{CH}$. In this sense, this professional figure must be able to plan a valorisation program of a selected case study, having in mind all the multiple aspects of an enhancement process, and being able to manage them. In particular, the main features to consider are:

- Recording the tangible aspect of the case study, identifying the most appropriate methodology and technology for surveying the case study and modelling the data, according to the needs and purposes of the work

- Acquiring the intangible aspects of a building/site, considering all the layers of information

- Making an in-depth analysis of the data acquired (tangible and intangible) and combine them to create strategies of interventions and products

- Community interactions with heritage, considering a heritage community as people who value specific aspects of Cultural Heritage which they wish, within the framework of public action, to sustain and transmit to future generations

The benefit and the difficulty are to conduct an interdisciplinary work, being aware of all the multiple processes contained in each point of the bullet lists for reaching communication goals between different disciplines, connecting digital technologies with humanities, in other words combining the technical advances and skills within a social science context.

Moreover, the pandemic situation in progress, represents an accelerator and an opportunity to further develop this topic, and find a strategy capable of integrating its management in the different social spaces in which it is revealed: institutional, community and media. The responsibility and the future of the Cultural Heritage are not only of the professionals who deal with its study, management, and conservation, but it is a broader matter that includes many subjects as the full citizenship. A $\mathrm{CH}$ project operated and accessed only by experts is out of date and without future, in as much as its effectiveness is measured in terms of social and cultural impact on society. For this reason, the article result is a "best practice" that uses digital technologies as a tool to engage people, produce cultural value and development, improving the impact of the work through communication and promotion. 


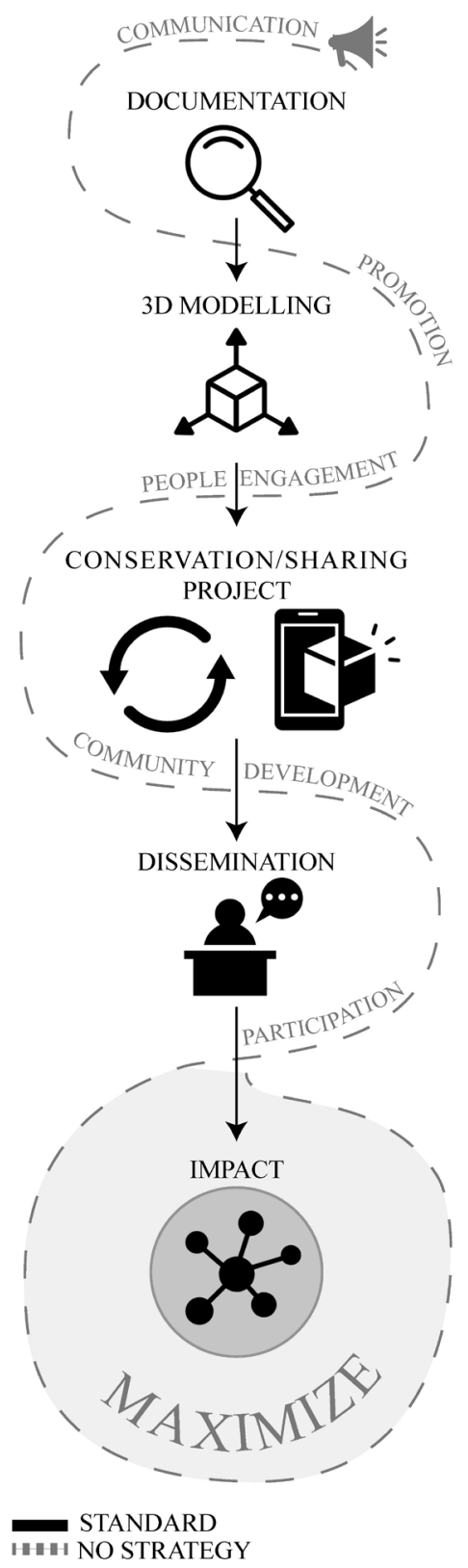

Figure 8. Communication and promotion actions leads to to a maximization of the impact of the "standard" methodology for a valorisation and conservation project.

\section{REFERENCES}

Catanese, R., 2013. 3D Architectural Videomapping. In Int. Arch. Photogramm. Remote Sens. Spatial Inf. Sci., Vol. XL5/W2, pp. 165-169, doi:10.5194/isprsarchives-L-5-W2-1652013,2013

Cooperation Program Interreg V-A, 2014: Communication Strategy 2014-2020. https://interregitaliasvizzera.eu/it/comunicazione/strategia-di-comunicazione/ (01 April 2021).

Culture Programme of the European Union (2015). Cultural Heritage Counts for Europe. http://blogs.encatc.org/culturalheritagecountsforeurope/outcome s/, (23 April 2021).
Dávila-Lorenzo, M., Saladrigas-Medina H.M., 2020: Public communication management model of heritage: a systemic alternative for the offices of the conservator and historian in Cuba. Proposal based on a case study. RLCS, Revista Latina de Comunicación Social, 77, 329-356. doi: 10.4185/RLCS-20201461.

Digital Innovation Observatories (2018). Cultural Heritage and activities: the roadmap for digital innovation report. http://www.osservatori.net, (26 June 2021).

European Commission, 2014: Communicating EU research and innovation guidance for project participants. https://ec.europa.eu/research/participants/docs/h2020-fundingguide/grants/grant-management/communication en.htm (01 April 2021).

European Commission. Comminication, Dissemination and Exploitation. Why they all matter and what is the difference? https://ec.europa.eu/research/participants/docs/h2020-fundingguide/imgs/quick-guide_diss-expl_en.pdf (27 June 2021).

European Commission (2019). H2020 Programme, Annotated Model Grant Agreement, version 2. https://ec.europa.eu/research/participants/data/ref/h2020/grants manual/amga/h2020-amga_en.pdf (27 June 2021).

Tartaglia, A., Fanzini, D., 2017. Il progetto di valorizzazione del patrimonio culturale e ambientale. In Tecnologie e processi per il progetto del paesaggio. Reti e modelli distrettuali. Ed. Maggioli, Santarcangelo di Romagna (RN), Italy.

Fassi, F., Achille, C., 2015. Rilievo e modellazione real-based della Statua della Madonnina. In Madunina di Milano by Carillo S., ed. La scuola di Pitagora, ISBN 978-88-6542-192-5.

Holley, R., 2010. Crowdsourcing: How and Why Should Libraries Do It?. In D-Lib Magazine, Vol. 16. doi:10.1045/march2010-holley.

MiBACT, 2004. Codice dei Beni Culturali e del paesaggio Decreto Legislativo 22 gennaio 2004, n. 42. Retrieved from https://www.beniculturali.

it/mibac/multimedia/MiBAC/documents/1226395624032 Codi ce2004.pdf (6 July 2021).

Oomen, J., Lora A., 2011. Crowdsourcing in the Cultural Heritage Domain: Opportunities and Challenges. Proceedings of the 5th International Conference on Communities and Technologies, pp. 138-149. New York, NY, USA, doi: $10.1145 / 2103354.2103373$.

Petraroia. P., 2014. La valorizzazione come dimensione relazionale della tutela. In Il Diritto dell'arte. 3. La protezione del patrimonio artistico, Negri Clementi, G., Stabile S. (curated by), Skira (Ed.), Milano, pp. 41-49.

Programma di cooperazione Interreg V-A, 2014: Strategia di Comunicazione 2014-2020. https://interregitaliasvizzera.eu/it/comunicazione/strategia-di-comunicazione/ $(01 / 04 / 2021)$

Spiridon-Ursu, P., Sandu, I., 2015. Conservation of the Cultural Heritage: from participation to collaboration. In ENCATC Journal of Cultural Management and Policy, Vol. 5 (1), pp. 4353. 